\section{Petronela Švikruhová ${ }^{1}$ Zuzana Kapsdorferová Ludmila Dobošová Radka Kataniková}

Article info: Received 30.08.2020. Accepted 17.12.2020.

UDC - 005.336.3 DOI - 10.24874/IJQR15.03-09

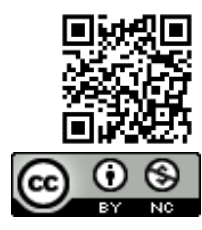

\title{
EFFECTIVE ESTABLISHMENT OF QUALITY MANAGEMENT SYSTEMS AND THEIR IMPACT ON BUSINESS PERFORMANCE
}

\begin{abstract}
In recent years, there have been significant changes in the world economy. Due to the predominance of supply over demand, rapidly spreading knowledge, the globalization of the business environment, the importance of quality in project management has increased dramatically around the world. The primary objective of this scientific paper is to evaluate the effectiveness of the quality management system in selected internal processes in the international IT company. The result will be a rationalization of internal processes, thereby reducing the workload of the software services team. This article is focused on the application of the DMAIC method on a specific Lean Six Sigma project within the international IT company.
\end{abstract}

Keywords: Quality management; Performance measurement; Process rationalization; DMAIC method; Lean Six Sigma method.

\section{Introduction}

Current business environment is characterized by dominant globalization and integration processes, accompanied by the development of new technologies and rapid market changes. To remain competitive in global business requires the continuous modernization of its technologies and processes. Lack of quality in process management leads to their failure. It is for this reason that many companies reach for techniques to increase the quality and efficiency of processes. It is no longer enough to pay attention only to products or services, today greater demands are placed on processes and their improvement. The Lean Six Sigma (LSS) method has developed into a comprehensive framework, which is one of the best practices in improving the quality of processes. During the implementation of the LSS project, the project team gradually detects existing as well as possible causes of problems, models future needs, proposes solutions and their implementation. The logical sequence of steps in the LSS project guarantees that quality is present in all aspects of the implementation. The correct application of LSS method companies achieves time and financial savings and higher quality processes. By improving business processes, the company can increase performance improvement, efficiency, but also increase customer satisfaction. Based on the above, the primary objective of the presented paper is to evaluate the effectiveness of the quality management system on selected internal processes in an international IT company. The result will be a rationalisation of internal processes, by reducing the workload of employees of the software services (SWS) team.

\footnotetext{
${ }^{1}$ Corresponding author: Petronla Švikruhová

Email: petronela.svikruhova@uniag.sk
} 


\section{Literature review}

Lean and Six Sigma as quality management methods that have been gaining significant popularity since they were proposed, were not integrated until the late 1990s and early $2000 \mathrm{~s}$ (M. L. George, 2002, George, 2003). From that period, they are frequently used in combination and referred to as LSS. Together, as LSS, they represent one of more dynamic and innovative strategies of management to improve quality of products and efficiency of manufacturing (Erdil et al., 2018, Aggogeri \& Mazzola, 2008). LSS combine the synergy between two valid methods: Six Sigma and Lean production.

Many authors have made attempts to define Lean, however there is no consistent definition of this term, a few defined it as a way to focus on customer, whereas others viewed it as way of reducing waste and identifying value.

Lean was developed from the Toyota Production System. After World War II, Eiji Toyoda and Taiichi Ohno at the Toyota Motor Company in Japan pioneered the concept of lean production (Womack \& Jones, 2014).

The Lean initiative take care of wastes reduction, uniform output, minimise lead time and process improvement (Drohomeretski et al., 2014, Everton et al., 2014; Alexandros and Loukas, 2012). Waste is defined as 'any human activity which absorbs resources but creates no value'. The value on the other hand in the business sense is defined as 'a capability provided to a customer at the right time at an appropriate price, as defined in each case by the customer' (Womack \& Jones, 2014).

A lean initiative approaches doing the right task, at the right time, in the right quantity to achieve relentless process flow while eliminating waste (Cheng \& Podolsky, 1996; "The Toyota Way to Healthcare Excellence: Increase Efficiency and Improve Quality with Lean," 2008), minimises lead time, work in process inventory and improve productivity with aiming at enhancing customer value (Albert, 2014).

In this paper we understand "Lean" as an integrated multidimensional approach encompassing wide variety of management practices based on philosophy of eliminating waste through continuous improvement (Gupta, Sharma, \& Sunder M., 2016). In this paper we used lean approach to determine the value of process by distinguishing valueadded work from non-value-added work.

On the other hand, Six Sigma is a data driven methodology which creates value through consistent process output by using statistical methods to identify and decrease or eliminate process variation (Erdil et al., 2018, Wang \& Chen, 2010). Six Sigma is a business management strategy used by many industries for quality improvement (Niñerola, Sánchez-Rebull, \& Hernández-Lara, 2019). Six Sigma identifies and eliminates mistakes, defects or failures that may affect processes (Arturo Garza-Reyes, Flint, Kumar, Antony, \& Soriano-Meier, 2014). In statistical terms, Six Sigma implies process output with no more than 3.4 defects in every million opportunities.

Both Six Sigma and Lean management have evolved into a comprehensive management systems. By their combination we will get the most prevalently used approach to process improvement. LSS has been adopted across all industries, not just manufacturing, as a successful methodology that focuses on four key issues: quality, productivity, cost and profitability (Evans \& Lindsay, 2014).

LSS has become a business model, a symbol of excellence, which brings a structured approach and data driven analysis with the goal of eliminating or reducing the sources of variation and waste (Erdil et al., 2018, Pamfilie, (Draghici), \& Draghici, 2012, Snee, 2010). LSS is an objective-oriented approach, which aims to maximise shareholder value by improving quality, speed, customer satisfaction, and costs (Laureani \& Antony, 2015, Mkhaimer, Arafeh, \& Sakhrieh, 2017, Timans, Antony, Ahaus, \& van Solingen, 
2012). There are several reasons to use Lean and Six Sigma together. Consider the following facts: Lean alone cannot reduce process variability, nor can Six Sigma alone significantly reduce process duration. The time and quality of the process go hand in hand, if we shorten the time, the quality will improve vice versa when we improve the quality, we shorten the time. Together, these two methods make it possible to reduce the costs resulting from the complexity of the processes. The simpler and faster process is cheaper, so Six Sigma can focus on operations that have added value for the customer. It thus adds to the overall quality.

LSS uses tools from both toolboxes in order to get the best from the two methodologies, increasing speed while also increasing accuracy. By merging tools and principles from both Lean and Six Sigma we gain the benefits of these both quality initiatives. LSS emphasises the quality and service improvement process offered by Six Sigma and the productivity and cost reduction tools offered by Lean management (Wang \& Chen, 2010).

Undeniably, the strength of LSS is its flexibility, which allows us to use the most suitable combination of different tools in extreme cases, it can be an exclusive use of the Lean method or an exclusive application of the Six Sigma method. Approaches used at individual projects vary and therefore these methods can be used individually or as an integrated methodology. However, when choosing tools, we must always keep in mind the specific needs and goals of individual projects, as well as the procedural maturity of the company.

\section{Research methodology}

The global information technology industry is a unique service industry, which deals with complex tasks. To overcome complex tasks, IT organizations need to implement DMAIC (acronym for Define, Measure, Analyze, Improve, and Control) approach of LSS to improve quality performance.

The proposed DMAIC approach of LSS creates a solid understanding of process control and management. It will first define all the needed requirements, measure the current processes, analyse the collected data, carry out the improvements and finally sustain these improvements with effective controls (Mkhaimer et al., 2017).

DMAIC is often described as an approach for problem solving, which is applicable to empirical problems ranging from wellstructured to semi-structured, but not to illstructured problems or pluralistic messes of subjective problems (Chakrabortty, Biswas, \& Ahmed, 2013).

Most Six Sigma implementations follow the DMAIC cycle. The five-step DMAIC process provides a structured and goal-oriented approach that incorporates a wide range of LSS tools into improvement already existing processes and is a proven framework in gaining significant business process improvement. (de Mast \& Lokkerbol, 2012, Tenera \& Pinto, 2014, Erdil et al., 2018, Ahmed, 2019).

Each step in the DMAIC process has a particular set of tasks and associated tools that start from the definition of the problem to ensuring that the improvements are sustained (Ismyrlis \& Moschidis, 2013, Augusto Cauchick Miguel, Satolo, Marcos Andrietta, \& Araújo Calarge, 2012, Uluskan, 2016, Uluskan, 2017).

\section{Result and Discussion}

After a detailed analysis, the top management of the company decided to launch an improvement project focused on the rationalization of internal processes within the SWS team. This team is performing vast amount of non-value add tasks related to software services processes. This drives manual workload associated with report preparations and prolongs cycle time between 
tasks. Business requirement are not met due to ongoing organization changes which effect the reporting, as the team is still working on division level which requires high granularity of the provided analysis. The main goal of this LSS project is to reduce working hours from current workload performance of 2400 hours by 640 hours per month by the end of April 2020. Essential for the success of the project is the establishment of a project team with strong management support. Our project team was established at the end of September 2019 and consisted of 14 members, whose roles were divided according to the standard Six Sigma project organization.

\subsection{Define Phase}

Every improvement project following the DMAIC approach starts with developing a project charter.

This phase deals with collecting voice of the customers (VOC) by doing surveys followed by the making of Project charter (Sunder, 2016). The project charter is shown Figure 1.

\begin{tabular}{|c|c|c|c|}
\hline \multicolumn{4}{|c|}{ Lean Six Sigma Project } \\
\hline \multicolumn{4}{|c|}{ Software Services Team Process Optimization } \\
\hline \multicolumn{4}{|c|}{$\begin{array}{l}\text { Opportunity Statement } \\
\text { Ig vast amount of non-value add tasks related to software services processes. This } \\
\text { iated with report preparation and prolongs cycle between tasks. The elimination } \\
\text { sks and redesign of the actual process will achieve productivity savings. }\end{array}$} \\
\hline \multicolumn{2}{|l|}{ Goal Statements } & \multicolumn{2}{|c|}{ Defect Definition } \\
\hline \multicolumn{2}{|c|}{$\begin{array}{l}\text { To reduce working hours from current workload } \\
\text { performance of } 2.400 \text { hours by } 640 \text { hours per month } \\
\text { by the end of April } 2020 \text {. }\end{array}$} & \multicolumn{2}{|c|}{$\begin{array}{l}\text { Each requested non-value add ad hoc task that was } \\
\text { performed. }\end{array}$} \\
\hline \multicolumn{3}{|l|}{ Financial and Other Benefits } & Planned internal costs \\
\hline $\begin{array}{l}\text { Harmonization: Yes } \\
\text { Job Roles Harmonized: } 15 \\
\text { Hours: } 640\end{array}$ & \multicolumn{2}{|c|}{$\begin{array}{l}\text { Improve the quality of the process } \\
\text { by appointing the best practices. } \\
\text { Increase the accuracy of the } \\
\text { process and the information } \\
\text { provided. Standardization through } \\
\text { functional roles and stand in } \\
\text { matrix. Increase value add of } \\
\text { information provided in reporting. }\end{array}$} & 19.833 BLUE $\$$ \\
\hline \multicolumn{4}{|c|}{ Idea Submitter: Petronela Švikruhová } \\
\hline
\end{tabular}

Figure 1. Project charter

Source: Own processing based on project meeting

The VOC identifies needs and requirements. There are many ways to collect data about customers need. In this paper we decided for active methods of gathering VOC. The survey was conducted on beginning of October 2019 and consisted of 23 questions (17 opened, 6 closed). The purpose of the survey was to identify the requirements of internal customers, specifically the SWS team. Understanding the VOC is one of the most important issues in the define stage (M. L. George, 2002).

We used MURAL to categorize and analyse the obtained data. MURAL as ICT (Information and communication technologies - ICT) tool for sharing unstructured information, such as pictures or audio files, supports participants to share their information (Lattemann, Siemon, Dorawa, \& Redlich, 2017). Since MURAL is based upon the development of a shared vision, it helps managers facilitate team collaboration and interaction across the organization (Jensen, 2015). This tool works like online brainstorming. By using MURAL team can take a more structured approach and collect better data. Team can work online, what make everyone equal, nullifies dominant voices what brings more ideas and more ownership by team. MURAL made collaboration on 
project much easier for our international team. Team could work together online without having to physically meet in one room. What is in this period much more than essential.

Based on the conducted survey we identified the requirements of SWS team:

- harmonize closing forecasting,

- remove manual workload related to vouchers,

- reduce forecast calls,

- confusion about responsibilities and not clearly set boundaries for support.
One of the most important steps of the LSS project aims to detect the Critical-to-Quality process factors (CTQs), considering the Customers opinion (Tenera \& Pinto, 2014). The VOC factors were deployed into requirements, which were then translated into CTQ specifications that can be measured. CTQs ensure that the project team tackle a problem that is important to the customer and affects the company's goals. The main CTQs defined from our VOC results can be seen in the Figure 2.

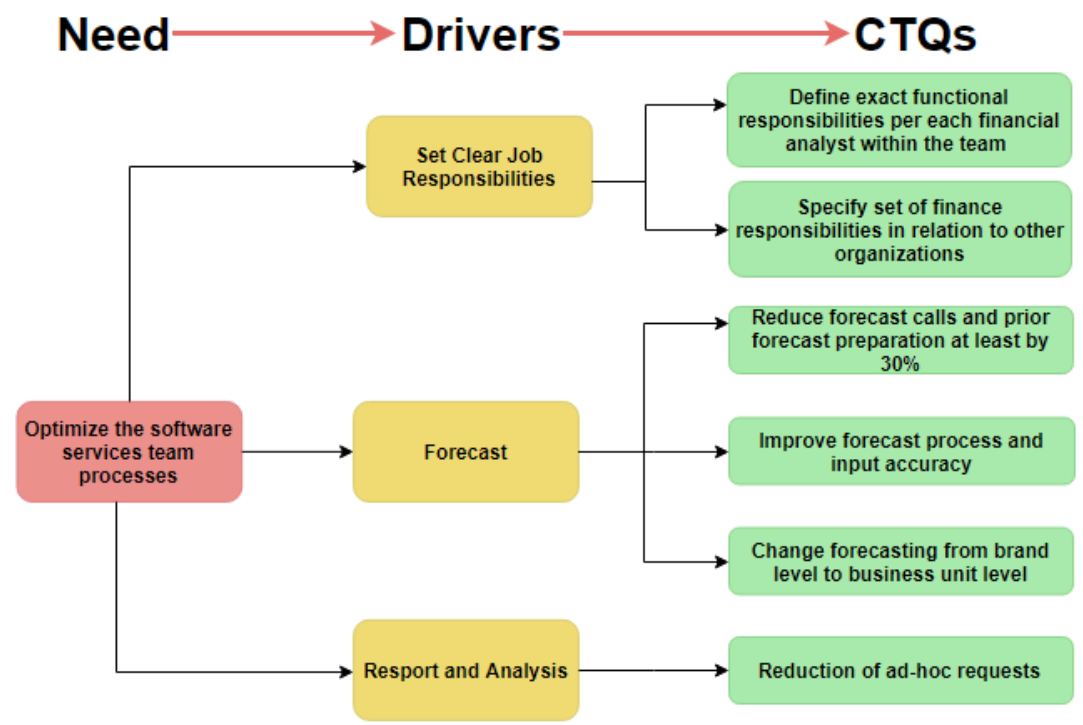

Figure 2. Critical-to-Quality process factors

Source: Own processing based on questionnaire survey

The next step in this phase was the process mapping. In the Process Mapping phase is necessary to focus on the process and their main stakeholders that will be later relevant to the improvement target that should be directly related to the identified CTQs. This detailed analyses consisted of large number of flowcharts, from perspective of employees and processes. To get a better view, on a high level process understanding the SIPOC (Supplier, Input, Process, Output, and Customer) diagrams were developed.
This diagram serves for detailing the involved stakeholders as well as for the main project activities, which need to be addressed. The crucial observation of process mapping is that processes are not standardized. There is huge dependency on $3^{\text {rd }}$ party input and different level of detailed input.

The next step in process analysis was the collection of Business as Usual (BAU) data. Based on the collected data, we have created a detailed process document that shows the key areas of the inefficient process. 
As you can see in the Figure 3 a significant proportion of work is dedicated to non-value add tasks, both during closing and nonclosing periods of the month.

Value adds tasks: valuable effort of the SWS team with business value, e.g. analysing data, reporting, etc.

Non-value adds tasks: activities, that don't contribute to the business, e.g. retrieving data, copying data, updating formulas, loading the data, etc.

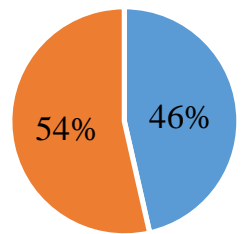

- Sum of Non Value Add per month - Sum of Value Add per month

Figure 3. Work proportion of the BAU Value Add vs Non-Value Add Work

\subsection{Measure and Analyze Phases}

The main objective in the "Measure" phase was to obtain data of current processes with respect to the stated project goal. Based on the obtained data, the project charter has been revised. The revised project charter, with a changed project objective as well as with increased planned internal costs (Figure 4).

Initially, it was necessary to perform a Pareto analysis of the workload in terms of processes and tasks that SWS team must perform.

\subsubsection{BAU by All Processes}

Nearly $60 \%$ of all BAU workload is driven by processes related to Forecasting and Reporting with high proportion of non-value add tasks. Approximately, $80 \%$ of all BAU non-value add workload is happening within processes - Forecasting, Reporting and Voucher creation (Figure 5).

\subsubsection{BAU Analysis by All Tasks}

Tasks with the highest proportion of nonvalue add were calls, gathering information, retrieving, formatting, validating and adjusting data. Approximately, $80 \%$ of NVA tasks are related to manual data preparation that has high potential for technical automation (Figure 6).

\begin{tabular}{|c|c|c|c|}
\hline \multicolumn{4}{|c|}{ Lean Six Sigma Project } \\
\hline \multicolumn{4}{|c|}{$\begin{array}{l}\text { Opportunity Statement } \\
\text { Software services is performing vast amount of non-value add tasks related to software services processes. This } \\
\text { drives manual workload associated with report preparation and prolongs cycle between tasks. The elimination } \\
\text { of workload, non-value add tasks and redesign of the actual process will achieve productivity savings. }\end{array}$} \\
\hline \multicolumn{2}{|l|}{ Goal Statements } & \multicolumn{2}{|c|}{ Defect Definition } \\
\hline \multicolumn{2}{|c|}{$\begin{array}{l}\text { To reduce working hours from current workload } \\
\text { performance of } 2.400 \text { hours by } 338 \text { hours per month } \\
\text { by the end of April } 2020 \text {. }\end{array}$} & \multicolumn{2}{|c|}{$\begin{array}{l}\text { Each requested non-value add ad hoc task that was } \\
\text { performed. }\end{array}$} \\
\hline \multicolumn{3}{|c|}{ Financial and Other Benefits } & Planned internal costs \\
\hline $\begin{array}{l}\text { Harmonization: Yes } \\
\text { Job Roles Harmonized: } 15 \\
\text { Hours: } 338\end{array}$ & \multicolumn{2}{|c|}{$\begin{array}{l}\text { Improve the quality of the process } \\
\text { by appointing the best practices. } \\
\text { Increase the accuracy of the } \\
\text { process and the information } \\
\text { provided. Standardization through } \\
\text { functional roles and stand in } \\
\text { matrix. Increase value add of } \\
\text { information provided in reporting. }\end{array}$} & 54.833 BLUE $\$$ \\
\hline \multicolumn{4}{|c|}{ Idea Submitter: Petronela Švikruhová } \\
\hline
\end{tabular}

Figure 4. Revised Project Charter

Source: Own processing based on project meeting 


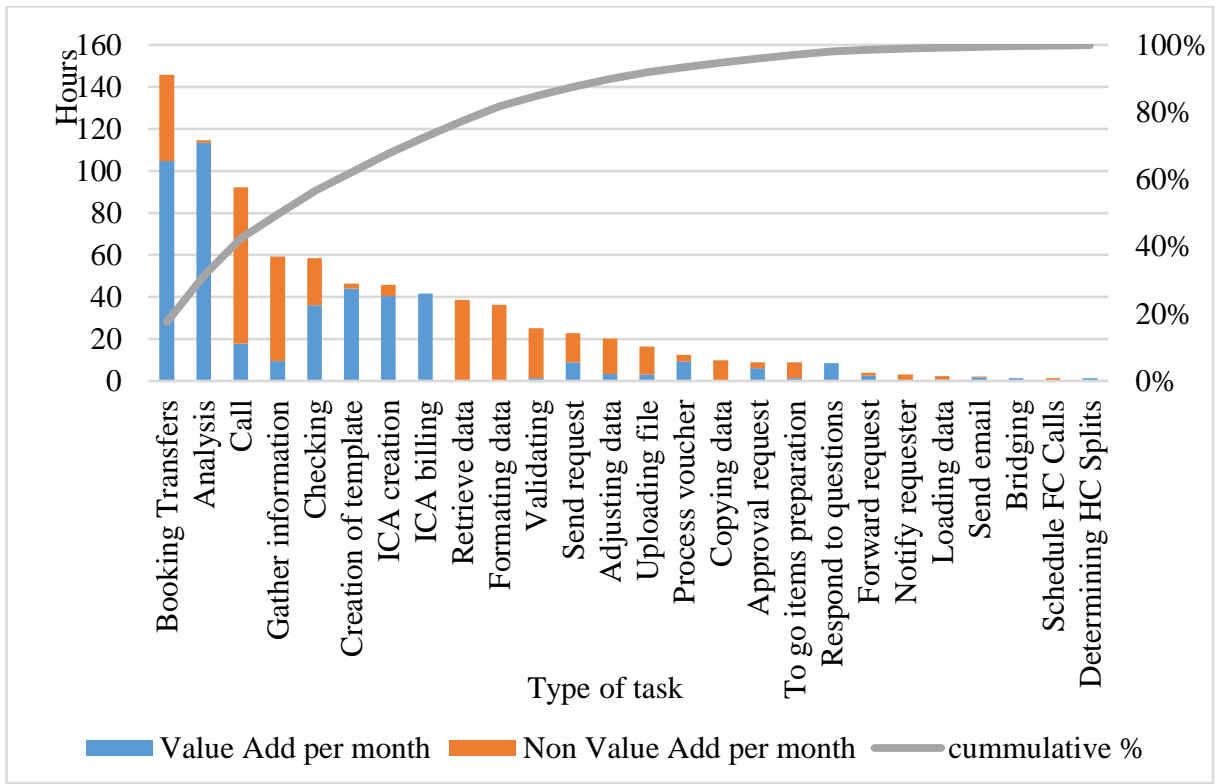

Figure 5 .Workload driven by processes per month (VA+NVA) Source: Own processing based on the obtained data

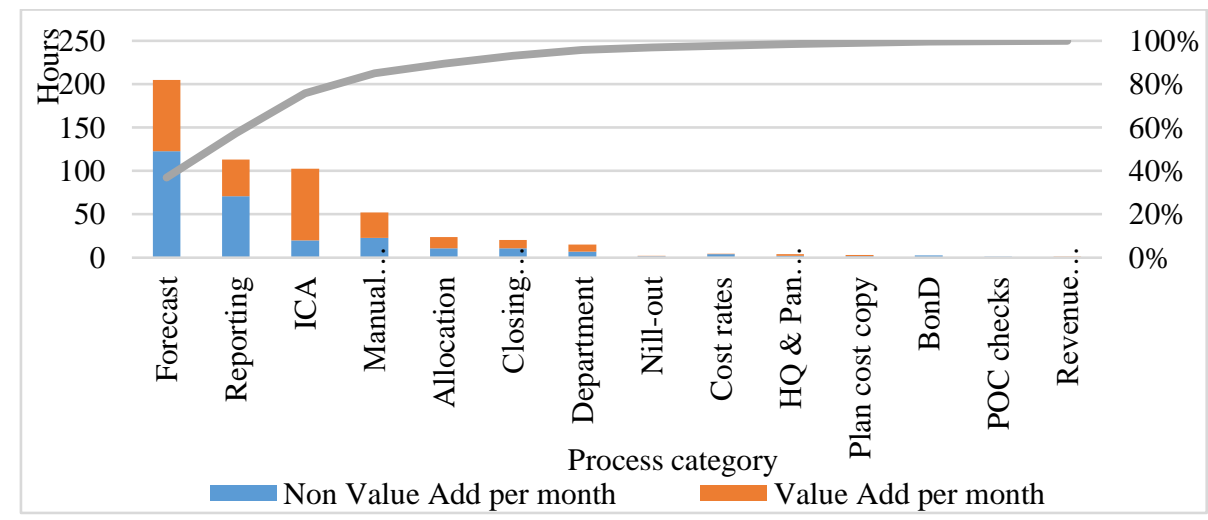

Figure 6. Total driven workload by tasks per month (VA + NVA) Source: Own processing based on the obtained data

\subsubsection{Measurement Execution}

To obtain all of the necessary data we conducted questionnaire survey from $17^{\text {th }}$ November $-13^{\text {th }}$ December 2019 . The survey was carried out within the SWS team members and consists of 8 opened and closed questions relating to:

- Identify time and date of receiving the Ad-hoc request (Occurance).
- Duration of Ad hoc request (when the employee started working on the request and how long it took).

- Ad hoc categorization and additional information for further analysis.

For the high-quality assurance we used in this LSS project quality control charts, which are considered as one of the seven basic quality tools for process improvement. The Control charts are effective tools for analysis of the 
variation of repetitive processes (Shewhart \& Deming, 1986, Manzini, Regattieri, Pham, \& Ferrari, 2012, Montgomery, 2013). According to our data and sample size we used $\mathrm{x}$-Bar and R-charts, which monitor mean and variation of a process based on samples taken in a given time. The control limits on both charts are used to monitor the mean and variation of the process going forward. If a point is out of the control limits, it indicates that the mean or variation of the process is out-of-control; assignable causes may be suspected at this point. A control chart as a graphical technique consists of a centre line (CL), upper control limit (UCL) and lower control limit (LCL). The upper and lower control limits are set at $\mp 3$ sigma from centreline.

We observed 2 outliers in occurrence of Ad Hoc Requests per measured period. An outof-control signal is given when an observation falls beyond the control limits. This means that process is instable. The instability of the process is characterized by unnatural and erratic fluctuations both sides of the control chart over a period. At the same time, we can observe a negative trend, as several observations are both above and below average. One of the outliers was at the point where the highest number of Ad hoc requests received was recorded. These requests were received at the end of the month. On the other hand, the second outlier field was at the point where the smallest number of Ad hoc requests received was recorded. Based on the above, the project team found that the main reason which caused that process is not under the statistical control is closing period and its related actions.

Second control chart showing the time needed to resolve Ad hoc requests. Even thought the data collection took plce from $17^{\text {th }}$ November - $13^{\text {th }}$ December 2019, the time required to solve these Ad hoc tasks was extended by 3 working days, i.e. until $18^{\text {th }}$ December 2019.

All the necessary data were collected through a short online questionnaire survey. The measured data are shown in hours. As well in duration of Ad Hoc resolutions we can observe that the process is out-of-control, as the one observation is outside the control field.

It is necessary to point out that although the process is stable by the occurrence of Ad hoc requests, the time required to resolve the request was longer. In the marked part (from day 9 to day 14) we can observe that despite the decreasing number of Ad hoc requests, the time required to resolve the requests increased, which caused that process in terms of time required to resolve Ad hoc requests is out-of-control with one outlier. The project team found that this was due to the acceptance of the Ad hoc request, which was laborintensive to process (Figure 7).

Team method, such as the Ishikawa diagram are mainly used to identify the causes of the problem. The Ishikawa diagram was constructed based on the list of possible causes that could have caused the problem.

As the central problem in this visual brainstorming approach we set the increasing amount of workload of the SWS team from customers. With respect to the possible causes we listed "Reports and Files ", "Roles and Responsibilities ", "Process" and "Time management" as the primary categories. Subcategories for each major cause can be seen in Figure 8.

Subcategories in the red boxes are considered to be the most probable causes that contribute most to the problem - "Report and Files" as well as "Processes". These findings are identical to those obtained with the questionnaire survey. 


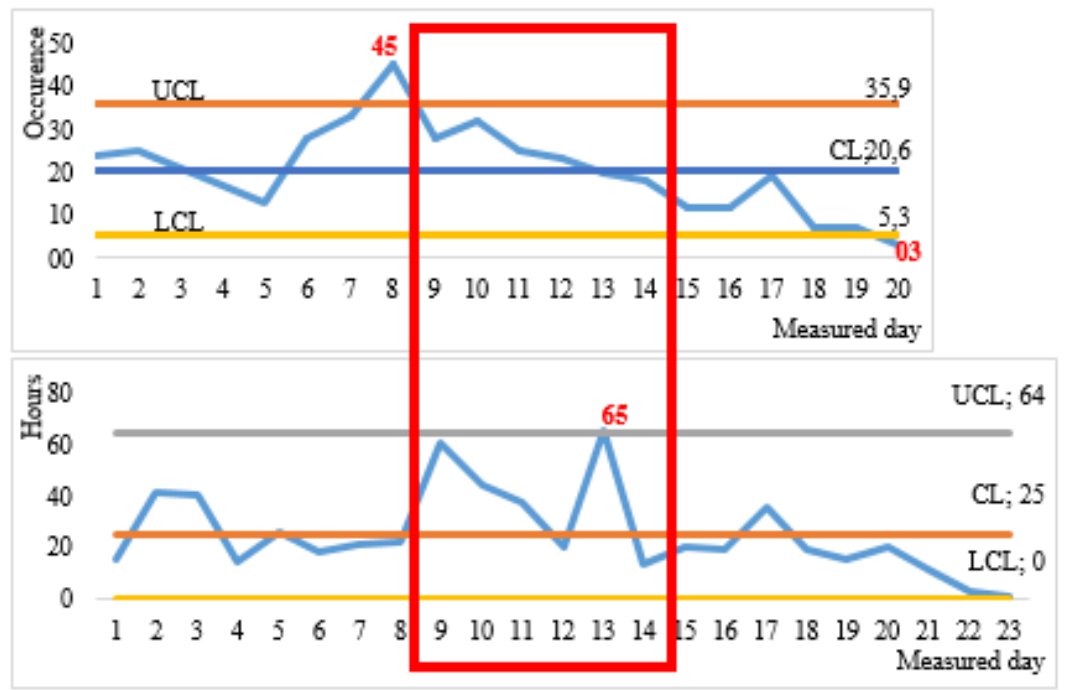

Figure 7. Comparison of control charts for occurrence and duration of Ad hoc requests Source: Own processing based on the collected data from questionnaire survey

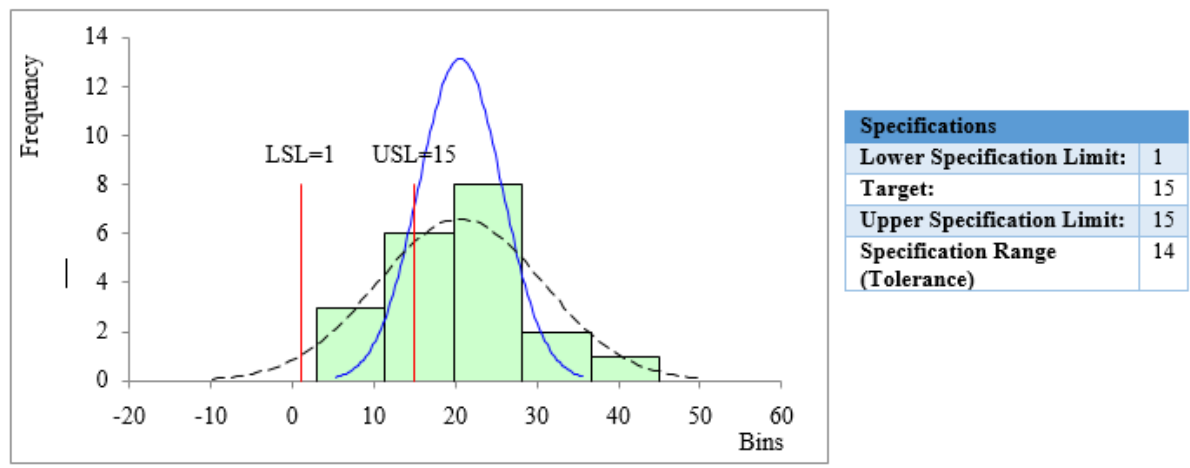

Figure 8. Process Capability Analysis

Source: Own processing based on the obtained data

The SWS team members complained about the lack of reliable sources and unstructured inputs, which take a lot of time to adjust.

Different approach to the similar process was identified as the potential for improvement. By unification of these processes we can rationalize them and thus decrease manual workload of SWS team. The SWS team members stated in the questionnaire survey that there is great confusion about responsibilities in the team. Curiously, the category - "Roles and Responsibilities" are not significant in terms of the results of the
Ishikawa diagram. Varous statistical tools were used in the "Analyze" phase. To test the hypothesis $\mathrm{H} 0$ we decided to use $t$-Test (Table 1). However, this test requires the assumption of normality of the phenomena, so it is advised to check normality first.

According to our sample size $(n)$ we decided to use Shapiro-Wilk Test with Known Mean. In hypothesis testing, if $\mathrm{p}$-value is lower than significant level, in case of XL Stat software by Addinsoft (version 2019.3.2), it is 0.05, the alternative hypothesis was rejected and null hypothesis was confirmed. 
Table 1. Tests

\begin{tabular}{|l|l|l|l|}
\hline \multicolumn{2}{|l|}{ Normality Test } & \multicolumn{2}{|l|}{ t-Test } \\
\hline W & 0,977713 & t & 2,470307074 \\
\hline p-value & 0,9013 & p-value & 0,011571 \\
\hline $\boldsymbol{\alpha}$ & 0,05 & $\boldsymbol{\alpha}$ & 0,05 \\
\hline
\end{tabular}

At the significance level of 0,95 we reject alternative hypothesis (H1) and we consider the file to be normally distributed.

After the normality test we performed the 1 Mean $t$-Test, which is aimed at verifying the null hypothesis (H0) against the alternative hypothesis (H1), which were set as follows:

- H0: The mean of Occurrence is less than or equal to 15

- H1: The mean of Occurrence is greater than 15

In hypothesis testing, if $p$-value is lower than significant level, in case of XL Stat software by Addinsoft (version 2019.3.2), it is 0.05, the $\mathrm{H} 0$ was rejected and $\mathrm{H} 1$ was confirmed.

We can be $95 \%$ confident that the mean of Occurrence is greater than 15 - the average number of Ad hoc requests received is greater than 15 throughout the year - there is space for improvement.

An important aspect in modern quality management is its measurability and therefore the next step in this paper is process capability analysis, which is a universal way of measuring quality. This method can be used when the company's strategy in quality management is clearly focused on continuous improvement and maximum customer satisfaction.

In Figure 8 we can see that the process we are monitoring is outside the tolerance limits and there is room for improvement. The project team set limits:

- $\quad$ Upper Specific Limit (USL) $=15$

- $\quad$ Lower Specific Limit (LSL) $=1$

These limits were selected based on the results of 1 Mean $t$-Test, where the occurrence of Ad hoc requests was found to be greater than 15 throughout the year.
Based on the above, the project team decided that company is willing to tolerate the maximum number of 15 Ad hoc requests received, which represents an upper specific limit and logically, it is not possible to prevent the occurrence of Ad hoc requests completely and therefore the project team decided to tolerate at least 1 received $\mathrm{Ad}$ hoc request, which represents the lower specific limit.

Key observations of this phases:

- Biggest areas for improvements for both BAU and Ad hoc tasks are in processes related to Forecasting, Reporting and Voucher creation.

- Tasks such as data preparation, querying, formatting, validating, adjusting, gathering information from different sources and unutilized time on call have the biggest proportion of non-value add work.

- Technical automation of manual work and files can significantly reduce the time and shift the focus of the financial analysts to analysis and other value added areas of work.

After the "Measure" and the "Analyse" phase, the project team decided to move to the "Improve" phase.

\subsection{Improvement phase}

Based on the analysis of the obtained data, the project team proposed an improvement scenario, which you can see in Figure 9 below.

This improvement scenario contains a specific proposal for improvement as well as the estimated savings that the implementation of the submitted changes would bring.

Color specifications reflects to the complexity of the individual tasks. The green color indicates the simple application in to the practice. Implementation shall be immediate. The yellow color, makes the planned improvement more difficult to apply. More 
time is required ti brig this change into the practice. The red color indicates the most difficult change to apply. However, this change requires the most time to implement, this change should lead, in long term, to the highest estimated savings for the company.

The improvement scenario serves the project team as better argumentation in front of the top management. These individual scenarios are based on measurements and analysis and were created as the most suitable choice for improving quality of the processes within SWS team.

Based on the information obtained in the previous phases, accrual accounting was a process that SWS staff considered to be manual and time consuming. In particular, they complained about tasks related to: preparing data, formatting data, gathering information, verifying various sources or retrieving data. From their point of view, these tasks cause the most workload.

\begin{tabular}{|c|c|c|}
\hline Status & Improvement scenario & $\begin{array}{l}\text { Estimated } \\
\text { savings }\end{array}$ \\
\hline & $\begin{array}{l}\text { 1. Reduce Services Cost Forecast from Monthly to } \\
\text { Quarterly }\end{array}$ & $1-1,5 \mathrm{FTE}$ \\
\hline $10 \mathrm{~K}$ & $\begin{array}{l}\text { 2. Raise clip for financial analysis/ manual bookings: } \\
\$ 10 \mathrm{k} \\
\text { a) } \$ 5 \mathrm{k} \text { strict clip level (no bundling) } \\
\text { b) Increase clip to } \$ 10 \mathrm{k} \text { and apply for both financial analysis } \\
\text { and bookings }\end{array}$ & $1 \mathrm{FTE}$ \\
\hline & 3. Shift financial support from Division to BU level & $2-3 \mathrm{FTE}$ \\
\hline
\end{tabular}

Figure 9. Improvement scenario

Source: Own processing based on the obtained data

Based on the above, the project team decided to take a measure and in cooperation with IT technicians they create a tool, which serves as automatic correction of irregularities in the balance sheet. This helped to reduce the manual workload of SWS team members. Project team set $\$ 5 \mathrm{k}$ strict clip level (no bundling). The project team considered this proposal as the easiest to apply in practice (green color), so they decided to implement it first.
In Figure 10 we can see the cumulative categories of manual entries within the SWS team for the last 6 months of 2019. Up to 54\% of the total number of manual entries represent entries below $\$ 5.000$ and up to $69 \%$ of all manual entries represent entries below $\$ 10.000$. The adoption of this improvement proposal has reduced the share of manual records by $24 \%$.

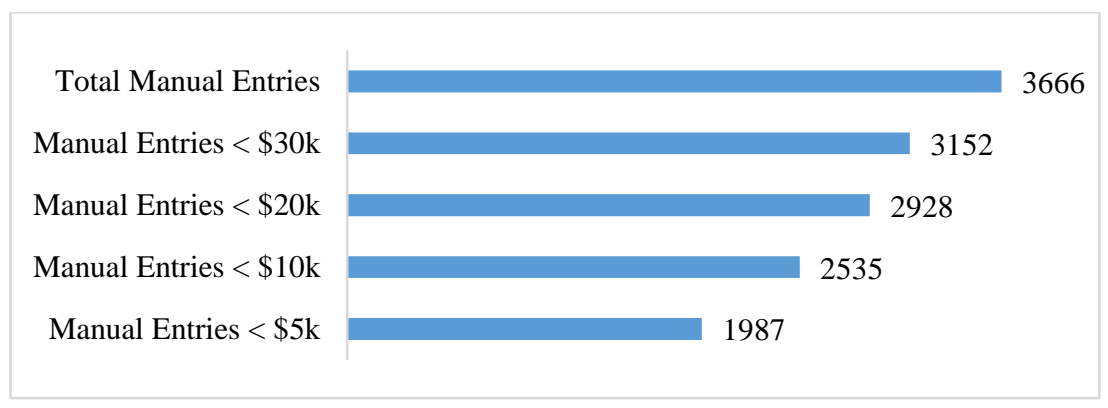

Figure 10. Number of manual entries for the last 6 months of 2019 Source: Own processing based on the obtained data 
The second proposal for improvement that was implemented reduction of forecast services costs - from monthly to quarterly. Currently two out of four identified actions were implemented. The other two action from improvement scenario were not implemented yet due to the due to the current situation related to the pandemic covid 19.

\section{Discusion}

In Slovakia, the Lean Six Sigma method is mainly used by companies operating in the engineering or automotive sectors. However, in recent years, its application in service companies has increased. Lean Six Sigma method is primarily used in companies to improve and manage processes.

After the systematic and organized selection we decided to chose this improvement project because it strategically influenced the examined company.

The basic process model for Lean Six Sigma projects is the DMAIC method, which represents an improved PDCA cycle leading to continuous improvement.

Undoubtedly strength of this method is its flexibility, which allows you to use the most appropriate combination of different tools - in the borderline case it can be a pure use of the
Lean method or an exclusive application of the Six Sigma method.

\section{Conclusion}

In this paper LSS methodology has been implemented through the DMAIC model in an information technology industry in Slovakia. The aim of the LSS project was to reduce process variation and also to reduce working hours from current workload performance of 2400 hours by 640 hours per month by the end of April 2020. The result is a rationalisation of internal processes, by reducing the workload of employees of the SWS team. Essential for the success of the project was the establishment of a project team with strong management support. Finally, we can appreciate that integrating Six Sigma into the ISO 9001 quality management system can help leverage resources for improvement, using a set of proven and trusted tools and techniques that save companies time and money. Saving costs and time is one of the main reasons for implementing a quality management system, and having a set of tools that lead a company in this endeavor can mean the difference between success and failure.

\section{References:}

Aggogeri, F., \& Mazzola, M. (2008). Combining Six Sigma With Lean Production to Increase the Performance Level of a Manufacturing System. Volume 4: Design and Manufacturing. Published. https://doi.org/10.1115/imece2008-67275

Ahmed, S. (2019). Integrating DMAIC approach of Lean Six Sigma and theory of constraints toward quality improvement in healthcare. Reviews on Environmental Health, 34(4), 427434. https://doi.org/10.1515/reveh-2019-0003

Albert, M. (2014, July 2). What Lean Really Means. Modern Machine Shop. https://www.mmsonline.com/columns/what-lean-really-means

Arturo Garza-Reyes, J., Flint, A., Kumar, V., Antony, J., \& Soriano-Meier, H. (2014). A DMAIRC approach to lead time reduction in an aerospace engine assembly process. Journal of Manufacturing Technology Management, 25(1), 27-48. https://doi.org/10.1108/jmtm-052012-0058 
Augusto Cauchick Miguel, P., Satolo, E., Marcos Andrietta, J., \& Araújo Calarge, F. (2012). Benchmarking the use of tools and techniques in the Six Sigma programme based on a survey conducted in a developing country. Benchmarking: An International Journal, 19(6), 690-708. https://doi.org/10.1108/14635771211284279

Chakrabortty, R. K., Biswas, T. K., \& Ahmed, I. (2013). Reducing process variability by using DMAIC model: A case study in Bangladesh. International Journal for Quality Research, 7(1), 127-1240.

Cheng, T. C., \& Podolsky, S. (1996). Just-in-Time Manufacturing: An introduction (1996th ed.). London, UK: Springer.

de Mast, J., \& Lokkerbol, J. (2012). An analysis of the Six Sigma DMAIC method from the perspective of problem solving. International Journal of Production Economics, 139(2), 604614. https://doi.org/10.1016/j.ijpe.2012.05.035

Erdil, N. O., Aktas, C. B., \& Arani, O. M. (2018). Embedding sustainability in lean six sigma $\begin{array}{llll}\text { efforts. Journal of Cleaner } & \text { Production, 198, } & \text { 520-529. }\end{array}$ https://doi.org/10.1016/j.jclepro.2018.07.048

Evans, J. R., \& Lindsay, W. M. (2014). An Introduction to Six Sigma and Process Improvement (2nd ed.). Stamford, USA: Cengage Learning.

George, M. (2003). Lean Six Sigma for Service: How to Use Lean Speed and Six Sigma Quality to Improve Services and Transactions (1st ed.). New York, USA: McGraw-Hill Education.

George, M. L. (2002). Lean Six Sigma: Combining Six Sigma Quality with Lean Production Speed (1st ed.). New York, USA: McGraw-Hill Education.

Gupta, S., Sharma, M., \& Sunder M., V. (2016). Lean services: a systematic review. International Journal of Productivity and Performance Management, 65(8), 10251056. https://doi.org/10.1108/ijppm-02-2015-0032

Ismyrlis, V., \& Moschidis, O. (2013). Six Sigma's critical success factors and toolbox. International Journal of Lean Six Sigma,4(2), 108-117. https://doi.org/10.1108/20401461311319310

Jensen, K. R. (2015). Inspiring a Collective Vision: The Manager as Mural Artist. The Ultimate Experience in Collaboration, 462.

Lattemann, C., Siemon, D., Dorawa, D., \& Redlich, B. (2017). Digitization of the Design Thinking Process Solving Problems with Geographically Dispersed Teams. Design, User Experience, and Usability: Theory, Methodology, and Management, 71-88. https://doi.org/10.1007/978-3-319-58634-2_6

Laureani, A., \& Antony, J. (2015). Leadership characteristics for Lean Six Sigma. Total Quality $\begin{array}{llll}\text { Management } \quad \text { B } & \text { Excellence, 28(3-4), }\end{array}$ https://doi.org/10.1080/14783363.2015.1090291

Manzini, R., Regattieri, A., Pham, H., \& Ferrari, E. (2012). Maintenance for Industrial Systems (Springer Series in Reliability Engineering) (2010th ed.). London, UK: Springer.

Mkhaimer, L. G., Arafeh, M., \& Sakhrieh, A. H. (2017). Effective implementation of ISO 50001 energy management system. International Journal of Engineering Business Management, 9, 184797901769871. https://doi.org/10.1177/1847979017698712

Montgomery, D. C. (2013). Statistical Quality Control. Hoboken, NJ, United States: Wiley.

Niñerola, A., Sánchez-Rebull, M. V., \& Hernández-Lara, A. B. (2019). Six Sigma literature: a bibliometric analysis. Total Quality Management \& Business Excellence, 1-22. https://doi.org/10.1080/14783363.2019.1652091 
Pamfilie, R., (Draghici), A. J. P., \& Draghici, M. (2012). The Importance of Leadership in Driving a Strategic Lean Six Sigma Management. Procedia - Social and Behavioral Sciences, 58, 187-196. https://doi.org/10.1016/j.sbspro.2012.09.992

Shewhart, W. A., \& Deming, E. W. (1986). Statistical Method from the Viewpoint of Quality Control (Dover Books on Mathematics) (F First Edition). New York, USA: Dover Publications.

Snee, R. D. (2010). Lean Six Sigma - getting better all the time. International Journal of Lean Six Sigma, 1(1), 9-29. https://doi.org/10.1108/20401461011033130

Sony, M. (2018). Industry 4.0 and lean management: a proposed integration model and research propositions. Production \& Manufacturing Research, 6(1), 416-432. https://doi.org/10.1080/21693277.2018.1540949

Sunder M., V. (2016). Lean six sigma project management - a stakeholder management perspective. The TQM Journal, 28(1), 132-150. https://doi.org/10.1108/tqm-09-2014-0070

Tenera, A., \& Pinto, L. C. (2014). A Lean Six Sigma (LSS) Project Management Improvement Model. Procedia - Social and Behavioral Sciences, 119, 912-920. https://doi.org/10.1016/j.sbspro.2014.03.102

The Toyota Way to Healthcare Excellence: Increase Efficiency and Improve Quality with Lean. (2008). Leadership in Health Services, 21(4). https://doi.org/10.1108/lhs.2008.21121dae.001

Timans, W., Antony, J., Ahaus, K., \& van Solingen, R. (2012). Implementation of Lean Six Sigma in small- and medium-sized manufacturing enterprises in the Netherlands. Journal of the Operational Research Society, 63(3), 339-353. https://doi.org/10.1057/jors.2011.47

Uluskan, M. (2016). A comprehensive insight into the Six Sigma DMAIC toolbox. International Journal of Lean Six Sigma, 7(4), 406-429. https://doi.org/10.1108/ijlss-10-2015-0040

Uluskan, M. (2017). Analysis of Lean Six Sigma tools from a multidimensional perspective. Total Quality Management \& Business Excellence, 30(9-10), 1167-1188. https://doi.org/10.1080/14783363.2017.1360134

Wang, F. K., \& Chen, K. S. (2010). Applying Lean Six Sigma and TRIZ methodology in banking services. Total Quality Management \& Business Excellence, 21(3), 301-315. https://doi.org/10.1080/14783360903553248

Womack, J. P., \& Jones, D. T. (2014, August 1). How to Root Out Waste and Pursue Perfection. Harvard Business Review. Retrieved from https://hbr.org

\section{Petronela Švikruhová}

Slovak University of

Agriculture in Nitra,

Nitra,

Slovakia

petronela.svikruhova@uniag.sk

\section{Zuzana Kapsdorferová}

Slovak University of Agriculture in Nitra,

Nitra,

Slovakia

zuzana.kapsdorferova@uniag.sk

\section{L'udmila Dobošová}

Slovak University of

Agriculture in Nitra,

Nitra,

Slovakia

ludmila.dobosova@uniag.sk

Radka Kataniková Slovak

University of Agriculture in

Nitra,

Nitra,

Slovakia

xkatanikova@uniag.sk 